\title{
Influence of Heat Input, Working Fluid and Evacuation Level on the Performance of Pulsating Heat Pipe
}

\author{
K. Rama Narasimha ${ }^{1 \dagger}$, S.N. Sridhara ${ }^{2}$, M.S. Rajagopal ${ }^{3}$ and K.N. Seetharamu ${ }^{4}$ \\ ${ }^{1}$ Centre for Emerging Technologies, Jain University, Bangalore, Karnataka, 562112, India \\ ${ }^{2}$ K.S. School of Engineering and Management, Bangalore, Karnataka, 560062, India \\ ${ }^{3}$ Global Academy of Technology, Bangalore, Karnataka, 560098, India \\ ${ }^{4}$ P.E.S. Institute of Technology, Bangalore, Karnataka, 560085, India \\ †Corresponding Author Email: k.ramanarasimha@gmail.com
}

(Received March 9, 2010; accepted July 14, 2010)

\begin{abstract}
An experimental study on pulsating heat pipe (PHP) is presented in this work. A closed loop PHP with a single U turn is fabricated and tested. The transient and steady state experiments are conducted and operating temperatures are measured. The experiments are carried out for different working fluids, heat input and for different evacuation levels. The derived parameters include thermal resistance and heat transfer coefficient of PHP. The results of these experiments show an intermittent motion of the working fluid at lower heat input. The temperature difference between evaporator and condenser at steady state is found lower for acetone compared to water, ethanol and methanol. Lower value of thermal resistance and higher value of heat transfer coefficient are observed in case of acetone compared to water, ethanol and methanol. Lower values of temperature difference between evaporator and condenser and thermal resistance and higher value of heat transfer coefficient are observed at atmospheric conditions of operation of PHP compared to evacuation conditions. The Power Spectral Density Analysis is also carried out on the results of these experiments using FFT technique to analyse the pulsating motion of the fluid in a PHP. In the Power Spectral Density analysis, the frequency distribution of temperature variation in PHP was observed over a wider range, signifying the periodic motion in the fluid flow of the liquid slug and vapour plug. This characteristic frequency corresponded to the characteristic time for a couple of adjacent vapour plug and liquid slug passing through a specific local wall surface in a PHP.
\end{abstract}

Keywords: Pulsating heat pipe, Electronic Cabinet cooling, FFT analysis.

\section{NOMENCLATURE}

$\begin{array}{ll}A_{s} & \text { Surface area of PHP }\left(\mathrm{m}^{2}\right) \\ h & \text { Heat Transfer Coefficient }\left(\mathrm{W} / \mathrm{m}^{2} \mathrm{~K}\right) \\ P & \text { Gauge Pressure inside the PHP }\left(\mathrm{N} / \mathrm{m}^{2}\right) \\ P H P & \text { Pulsating Heat Pipe } \\ P S D & \text { Power Spectral Density }\end{array}$

\section{INTRODUCTION}

Thermal management is the challenge of the day in electronic product development. Presently, the chip heat flux level ranges between 40 to $120 \mathrm{~W} / \mathrm{cm}^{2}$. It is expected to increase to $200 \mathrm{~W} / \mathrm{cm}^{2}$ in the next few decades. Several cooling methods are employed to cool the electronic devices. The Oscillating or Pulsating Heat Pipe (PHP) is being explored for cooling electronic devices with promising results. The PHP is simple in structure with a small diameter coil filled with certain working fluid in it and extended from the heat source to sink. PHP uses the technique of transporting

\author{
$Q \quad$ Heat Input (W) \\ $R \quad$ Thermal Resistance $(\mathrm{K} / \mathrm{W})$ \\ $T_{e} \quad$ Evaporator Wall Temperature $\left({ }^{0} \mathrm{C}\right)$ \\ $T_{c} \quad$ Condenser Wall Temperature $\left({ }^{0} \mathrm{C}\right)$ \\ $t \quad$ Time (s)
}

the working fluid by means of differential pressure across liquid slugs and vapor plugs from evaporator to condenser and back. The fluid from the evaporator is pushed towards the condenser in the form of discrete liquid slugs and vapor bubbles. The vapor gets partially condensed at the condenser and looses the heat and returns to evaporator to complete the cycle. The heat transfer in a PHP is due to the sensible heat and latent heat combination (Wilson 2006). PHP, first proposed by Akachi $(1993,1996)$ as a passive device is gaining attention of many investigators. Both experimental and numerical investigations on PHP's and their performance are reported in the literature though not in 
sufficient numbers. The experimental investigations mainly focus on flow visualization and measurement of temperature. Numerical investigations deal with various PHP models and performance evaluation.

Thermal modeling of vertically placed unlooped and looped PHP with three heating sections and two cooling sections was presented by Shafii et al. (2001). The dimensional governing equations of mass, momentum and energy were solved using an explicit scheme. They observed that the number of vapor plugs is reduced to the number of heating sections no matter how many vapor plugs were initially in the PHP. Zhang and Faghri (2002) studied the heat transfer phenomena in the evaporator and condenser sections of a PHP with open end for analyzing thin film evaporation and condensation. The heat transfer solutions were applied to the thermal model of the PHP and a parametric study was presented. Zhang et al (2002) developed the empirical correlations to amplitude and circular frequency of oscillations for liquid vapour pulsating flow in a vertically placed $U$ - shaped miniature tube using momentum and energy equations. The authors showed that the initial displacement of the liquid slug has a marginal effect on the amplitude and angular frequency of oscillation.

Zhang and Faghri (2003) studied numerically the oscillatory flow in a PHP with arbitrary number of turns. The authors considered a vertical PHP with evaporator section at the top and condenser section at the bottom. The governing equations are non dimensionalised and the problem was analyzed with eight non - dimensional numbers. The effects of number of turns, length of the heating and cooling section were investigated. In the above works, heat transfer in PHP is studied considering the pressure difference between evaporator and condenser as the driving force.

A mathematical model which deals with the oscillating motion of the fluid in a PHP was proposed by Ma et al. (2006) based on the temperature difference between the evaporator and condenser as the driving force. This model established the relation between oscillating frequency and geometry, thermal potential, fill ratio, working fluid and operating temperature. The results of their study are used to understand the mechanism governing the pulsating phenomenon in a PHP. The authors relate the pressure difference between evaporator and condenser with the temperature difference using Clausius - Clapeyron equation. The model was solved for the displacement of the slug and highlights the characteristics of PHP in the saturation region. The authors considered Water and Acetone as the working fluid in their study.

Rama Narasimha et al. (2010) used the Ma et al. (2006) model and solved the governing equation for the displacement and the velocity of the slug using explicit embedded Runge - Kutta formula, the Dormand Prince pair. Their results showed that the slug velocity is influenced by the fill ratio, the diameter of the tube, the operating temperature, the temperature difference between evaporator and condenser and the working fluid. They studied the flow characteristics of PHP with non - dimensional numbers viz. Poiseuille Number, Capillary Number and Eckert Number.
Many experimental works on PHP are also reported in the literature. Piyanun Charoensawan et al. (2003) conducted experimental investigations on a range of PHPs. The closed loop PHPs were made of copper tubes of inner diameters $2 \mathrm{~mm}$ and $1 \mathrm{~mm}$. Water, ethanol and $\mathrm{R}-123$ were used as the working fluids. The authors identified that the relative share of sensible and latent heat in PHP is influenced by the working fluid. They also showed that the type of flow (i.e. slug/annular flow), the average flow velocity and overall pressure drop in PHP depends on the working fluid. They found that the bubble nucleation, collapse, shapes and bubble pumping action were influenced by the working fluid. In their experiments, they observed better performance of PHP with water at vertical orientation with $2 \mathrm{~mm}$ inner diameter. With $1 \mathrm{~mm}$ diameter tubes, they obtained better results with $\mathrm{R}-$ 123 and ethanol.

An experimental study on PHP was carried out by Zhang et al. (2004) with FC - 72, ethanol and water as working fluids. The experimental set up consists of copper tubes of inner diameter $1.18 \mathrm{~mm}$ and the number of turns was 3 . The authors observed that the amplitude of thermal oscillations reported was small for FC -72 compared to water and Ethanol due to its lower surface tension. The oscillation movement in the channels was found to be faster in case of FC - 72 compared to the other two fluids. This quick movement of $\mathrm{FC}-72$ in the channels was attributed to its lower latent heat value. They suggested water as the better working fluid beyond a minimum heat input. They also showed that $\mathrm{FC}-72$ is more suitable for low heat flux situations.

Ma et al. (2008) conducted an experimental study on a nanofluid PHP to investigate the nanofluid effect on the heat transport capability. The nanofluid used in the study consisted of HPLC grade water and 1 vol\% diamond nano particles of $5-50 \mathrm{~nm}$. The authors used alloy 122 copper tubes of inner diameter $1.65 \mathrm{~mm}$ and outer diameter of $3.18 \mathrm{~mm}$ in their experimental setup which consisted of 12 turns. A filling ratio of $50 \%$ was used in the study. The experiments were conducted by varying the heat input from 0 to $360 \mathrm{~W}$ and the effect of operating temperature and heat input on the performance of PHP was studied. The operating temperature was varied between $0^{\circ} \mathrm{C}$ and $70^{\circ} \mathrm{C}$. In the experimental setup the usual working fluid (water) is used along with the HPLC grade water to demonstrate the nanofluid effect. Their experimental results showed that the heat transport capability of PHP increases rapidly when it is charged with nanofluid and a thermal resistance of $0.03^{0} \mathrm{C} / \mathrm{W}$ was reported at $336 \mathrm{~W}$. It was also observed that the heat transport capability of PHP increases with the increase in the operating temperature. The start - up and steady thermal oscillation of a PHP was studied by Xu and Zhang (2005). The experimental set up was built with copper tubes of $2 \mathrm{~mm}$ inner diameter and FC -72 is used as the working fluid. The authors observed two types of the start up processes during the working of PHP. The first one was at low heat input of $10 \mathrm{~W}$ named as sensible heat receiving start up process. This process was accompanied by a temperature overshoot. The second process was at high heat input of $25 \mathrm{~W}$ identified as the sensible heat 
receiving process incorporating a smooth oscillation transition period with oscillatory flow. The authors also performed the power spectrum analysis to analyze the thermal oscillation of PHP. The studied frequency corresponds to the time that a couple of adjacent vapor plug and liquid slug passing through a specific wall surface. At low heat input, the oscillation flow in PHP shows a random behavior with wider frequency range. At higher heat inputs, the authors observed the periodic behavior in the oscillatory flow. The non continuous power spectrum showed couple of dominant frequencies.

Khandekar (2004) demonstrated the existence of multiple quasi - steady state in a PHP by developing an experimental test rig of a single loop PHP made of cooper tubes of inner diameter $2 \mathrm{~mm}$ and outer diameter $3 \mathrm{~mm}$. The experiments were conducted for heat inputs of $10 \mathrm{~W}, 15 \mathrm{~W}$ and $20 \mathrm{~W}$ with ethanol as the working fluid at $60 \%$ fill ratio and continuous online data were recorded for 12 hours. The multiple quasi steady states observed were named as steady state 1,2 and 3 . The flow in steady state 1 was unidirectional with alternate fluid movement and stop over due to which there was an intermittent heat transfer. Higher value of thermal resistance was observed in steady state 1 . In steady state 2 , a tendency of liquid hold - up was observed in the condenser section which made the evaporator zone drier and hotter. Extremely poor thermal performance was reported in the steady state 2 . The author demonstrates that steady state 3 resulted in unidirectional flow pattern with no stop - over leading to least thermal resistance. It was showed that the churn flow takes place in the evaporator and slug flow in the condenser zones. It was also identified that continuous heat transfer takes place in the evaporator and condenser at steady state 3 .

Thus from the literature survey it is clear that not many experimental work is reported on single loop PHP. It is also observed that only one fluid i.e. ethanol is used as the working fluid in the experiments of single loop PHP. Moreover the experiments are carried out at a particular evacuation level. No data is available related to single loop PHP for other fluids and at different evacuation conditions. Thus in the present investigations, fluids like acetone, methanol and water in addition to ethanol are considered and the experiments are carried out for single loop PHP. The levels of evacuation maintained during the present experiments are 0.7 bar, 0.8 bar and atmospheric whereas in the literature one level of evacuation used has not been mentioned for single loop PHP. Various performance indicators such as thermal resistance and heat transfer coefficient are evaluated and analyzed for different heat loads. The measured temperature fluctuations are subjected to Power Spectral Density Analysis using FFT technique.

\section{EXPERIMENTAL SETUP}

Figure 1 shows the schematic diagram of the experimental setup. In this setup, copper is used as the tube material with inner diameter of $2 \mathrm{~mm}$ and outer diameter of $3 \mathrm{~mm}$. In order to visualize the fluid flow in the PHP, a glass tube is connected to the copper tubes for a length of $65 \mathrm{~mm}$. In the present study, borosilicate glass of inner diameter $2 \mathrm{~mm}$ and outer diameter $3 \mathrm{~mm}$ is employed. Silicon rubber tubes of $2 \mathrm{~mm}$ inner diameter and $4 \mathrm{~mm}$ outer diameter are used as connectors between glass and copper tubes, both in the evaporator and condenser section. The silicon rubber tubes are employed as connectors because they are thermal insulators and can withstand high temperatures up to $400^{\circ} \mathrm{C}$. They are leak proof and expand at higher temperatures. As the glass tube is connected to the copper tubes both in the evaporator and condenser sections through these silicon rubber tubes, the copper tube is not in direct contact with the glass tube. Since the thermal conductivity of the glass tube is extremely low compared to copper tube, very little heat will be flowing through the glass wall. Thus glass tube can be considered as adiabatic which many authors have used in the earlier literature (Khandekar 2004). It is also observed during the experiments that the glass section is very slightly warmer and can be comfortably touched by hand. The purpose of the glass tube is to check the flow configuration. The flow configuration corresponds to sections other than the evaporator and condenser.

In order to maintain unidirectional fluid flow in the circuit, a non-return valve is used. A tape heater of heating capacity $0-50 \mathrm{~W}$ is used to heat the working fluid. T-type thermocouples are used for the temperature measurement. The operating temperature range of these $\mathrm{T}$ type thermocouples is $-50^{\circ} \mathrm{C}$ to $400{ }^{\circ} \mathrm{C}$ with a maximum error of $\pm 0.1^{\circ} \mathrm{C}$. In the present setup totally six thermocouples are used, four in the evaporator section and two in the condenser section.

The thermocouples are fixed to the copper tube by drilling a small indentation on the copper tube and fixing the beed into the indentation by force fit. The thermocouple wire is then taken around the part of the circumference before taken out. A Krypton tape is wound on the thermocouple beed and the thermocouple wire. The thermocouple calibration is performed using saturated steam and ice bath even though the calibration curve is supplied by the thermocouple supplier. A temperature data logger is used for recording the temperature values. The temperature values are recorded with a frequency of $1 \mathrm{~Hz}$.

There is always a risk of the working - fluid entering into the electronic components such as vacuum gauge. Hence a fluid retaining container is introduced between the vacuum gauge and the main circuit of PHP. The container is designed with the hose at an elevation and a trough below to trap the liquid. This restricts the fluid entering the gauge sensor. The container is made up of stainless steel and it has two ports on top for the safe passage of the suction.

A direct drive double stage Rotary Vacuum Pump with in-built gas ballast is used to create the vacuum in the setup. The vacuum level better than $10^{-3} \mathrm{~m}$ bar can be created using the pump. A digital high pressure Pirani gauge (Model DHPG-10250) from HINDHIVAC is used to measure the vacuum. The glass wool is uniformly smeared throughout the entire set-up so as to ensure that the experimental setup is well insulated.The experimental setup is operated with four working fluids viz., water, acetone, ethanol and methanol. 


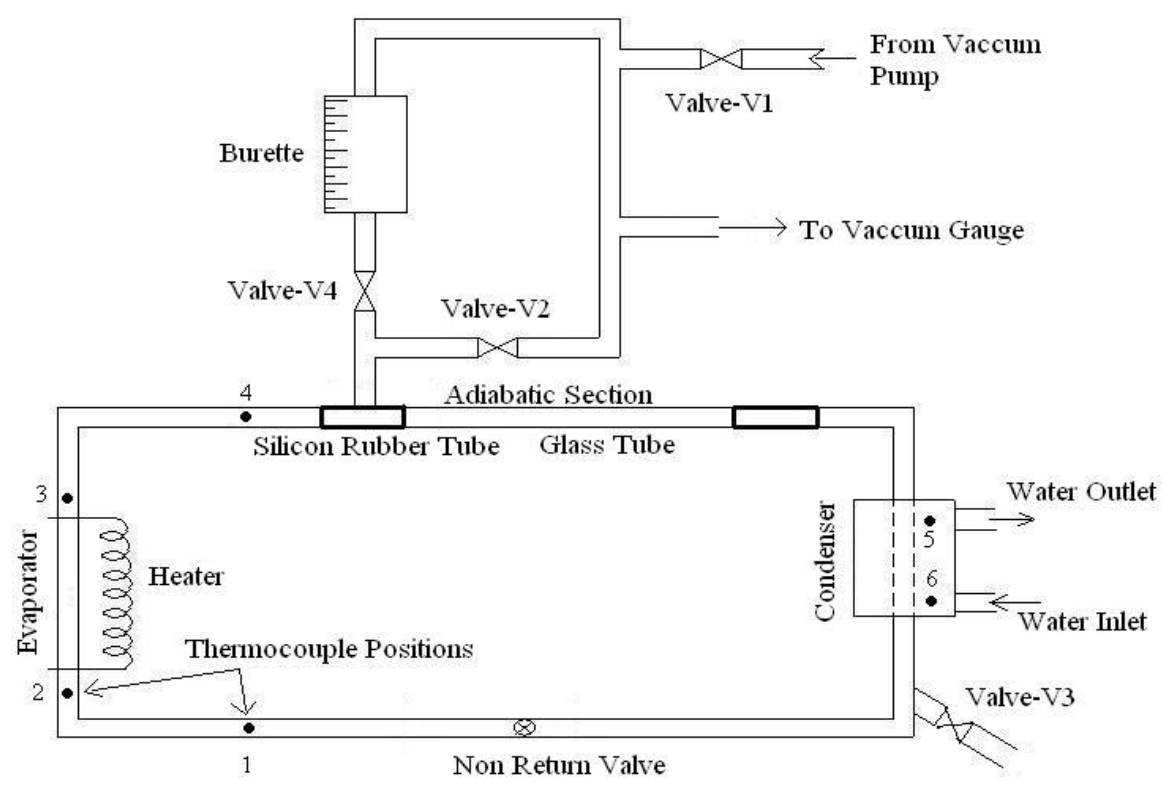

Fig. 1. Schematic of single turn PHP

\section{Experimental Procedure}

The experimental setup shown in Fig.1 is used for experimentation and the following procedure is adopted during the present transient experiment:

1. Before filling the working fluid, it is ensured that there is no other fluid exists inside the tubes of PHP.

2. The valves $V_{3}$ and $V_{4}$ are kept closed while the valves $V_{1}$ and $V_{2}$ are opened (Fig. 1). Then the PHP system is evacuated to the required level using the vacuum pump. The evacuation level is maintained at the required value with the help of Swagelok valves. In the present work, the experiments were carried out with three evacuation levels of 0.7 bar, 0.8 bar and 1 bar respectively considering the boiling point of the fluids used at these pressures.

3. Once the evacuation of the PHP system is complete, the valves $\mathrm{V}_{1}$ and $\mathrm{V}_{2}$ are closed. The required amount of working fluid is then filled by opening the valve $\mathrm{V}_{4}$ (Fig. 1). It is reported in the literature (Khandekar 2004) that the PHP works as a true pulsating device when the fill ratio is between $20 \%$ to $80 \%$ and it is also stated that $50 \%$ is the optimum fill ratio for a PHP. Considering this, a fill ratio of $60 \%$ is used during the present experiments and the PHP is filled with the working fluid with a fill ratio of $60 \%$.

4. The cooling water is allowed to the condenser section of PHP from the constant water bath and the amount of cooling water is controlled in such a way that the temperature rise of cooling water in the condenser is always between $1^{0} \mathrm{C}$ to $2^{0} \mathrm{C}$.

5. The temperature data logger is then switched on to record the temperature readings and the frequency of data logging is adjusted to $1 \mathrm{~Hz}$.

6. The required wattage is set using the power supply unit. In the present work, the experiments were conducted by varying the heat inputs from $7 \mathrm{~W}$ to $12 \mathrm{~W}$ in steps of $1 \mathrm{~W}$.

7. Transient experiments are conducted with different working fluids viz. acetone, ethanol, methanol and water and the various temperatures are recorded with the help of data logger. The experiments are continued till steady state is reached.

\section{ReSUlts AND DiscusSiON}

\subsection{Effect of Heat Input on Temperature}

As there is a continuous pressure pulsation during the flow in a PHP, there will be fluctuations in both the evaporator and condenser temperatures even at steady state. There are four thermocouples mounted in the evaporator section and two in the condenser section and hence the uncertainty in the evaporator temperature and condenser temperature $\mathrm{U}_{\mathrm{e}}$ and $\mathrm{U}_{\mathrm{c}}$ are evaluated respectively as (Kline et al. 1953),

$$
\begin{aligned}
& \% U_{e}=\sqrt{\left(\frac{\Delta T_{1}}{T_{1}}\right)^{2}+\left(\frac{\Delta T_{2}}{T_{2}}\right)^{2}+\left(\frac{\Delta T_{3}}{T_{3}}\right)^{2}+\left(\frac{\Delta T_{4}}{T_{4}}\right)^{2}} \\
& \% U_{c}=\sqrt{\left(\frac{\Delta T_{5}}{T_{5}}\right)^{2}+\left(\frac{\Delta T_{6}}{T_{6}}\right)^{2}}
\end{aligned}
$$

The maximum uncertainty obtained in the temperature readings using Eqs. (1) and (2) is about 5\%. A typical transient plot showing the variation of evaporator wall temperature with time at the initial evacuation pressure of 0.7 bar for acetone is shown in Fig. 2. From Fig. 2, it can be seen that the variation of evaporator temperature with respect to time is periodic in nature at steady state. As there is a continuous pressure pulsation during the flow in a PHP, the evaporator temperature versus time curve is periodic in nature. It is also clear that the fluctuations in the evaporator temperature is more at 
lower heat input of $7 \mathrm{~W}$ due to intermittent motion of the working fluid. It is also clear that the system takes more time to reach the steady state at lower heat input of $7 \mathrm{~W}$.

Figure 3 shows the variation of condenser wall temperature with respect to time at different heat inputs for acetone at the initial evacuation pressure of $0.7 \mathrm{bar}$. It is clear from Fig. 3 that the variation of condenser temperature is less at lower heat input of $7 \mathrm{~W}$ compared to higher heat input of $11 \mathrm{~W}$ and $12 \mathrm{~W}$. This is because of the very slow and intermittent motion of the working fluid at lower heat input. As the movement of the working fluid is slow at lower heat input due to lower energy levels, the hot fluid takes more time to reach the condenser from the evaporator. Thus the rise in the temperature of the cooling fluid is very less which results in lower values of condenser temperature at lower heat input.

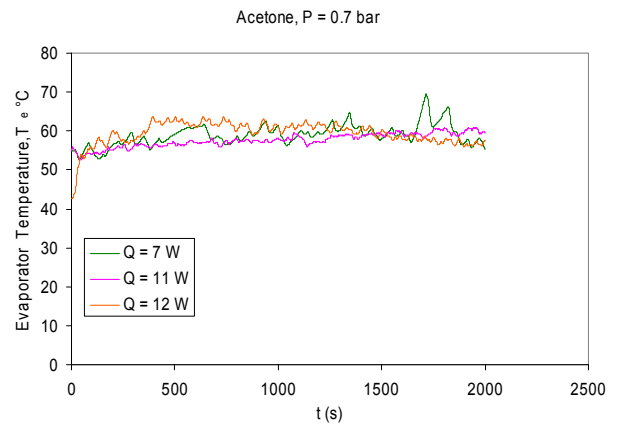

Fig. 2. Effect of heat input on evaporator Temperature for acetone at $\mathrm{P}=0.7 \mathrm{bar}$

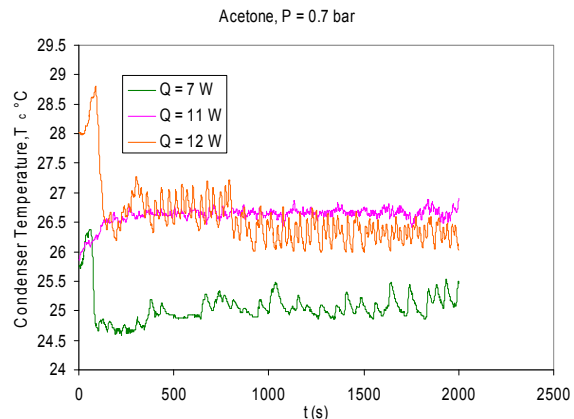

Fig. 3. Effect of heat input on condenser temperature for acetone at $\mathrm{P}=0.7 \mathrm{bar}$ Acetone, $P=0.7$ bar

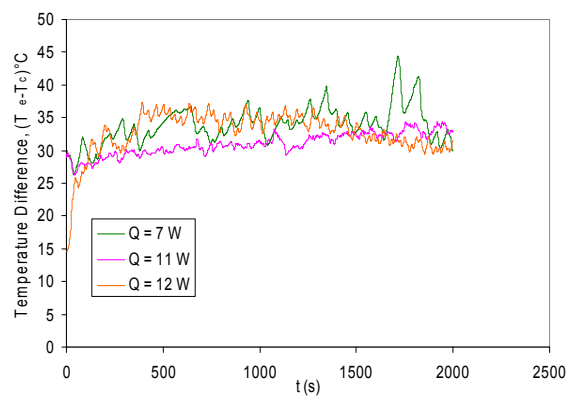

Fig. 4. Effect of heat input on temperature difference for acetone at $\mathrm{P}=0.7 \mathrm{bar}$

Figure 4 shows the plot of temperature difference with respect to time for acetone at different heat inputs at evacuation pressure equal to 0.7 bar. From Fig. 4 it is evident that the temperature difference between evaporator and condenser decreases with increase in heat input. As the movement of the fluid is very slow at lower heat input which is associated with lot of fluctuations, the temperature difference between evaporator and condenser is higher at lower heat input. It is also observed from Fig. 4 that the temperature difference between evaporator and condenser increases with increase in time up to 500 seconds beyond which it reaches a quasi steady state.

\subsection{Effect of Evacuation Pressure on Temperature}

During the course of present work, transient experiments were conducted by evacuating the PHP tubes initially. The experiments were conducted for different evacuation levels of 0.7 bar, 0.8 bar and 1 bar. The variation of evaporator wall temperature with respect to time for acetone at a heat input of $11 \mathrm{~W}$ and at different evacuation levels is indicated in Fig. 5. From the figure it can be seen that the evaporator temperature is slightly higher at evacuation level of 0.7 bar compared to atmospheric conditions. As more vapor exists in the PHP tube at 0.7 bar in view of lower saturation temperature, less heat is being transferred from the wall to the fluid. This results in higher evaporator wall temperature at 0.7 bar.

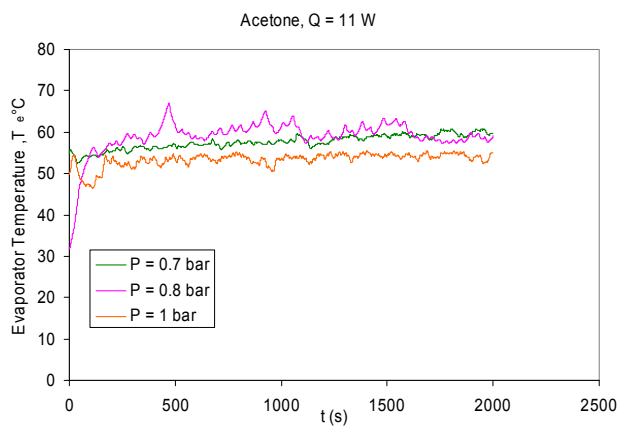

Fig. 5. Effect of evacuation on evaporator temperature for acetone at $\mathrm{Q}=11 \mathrm{~W}$

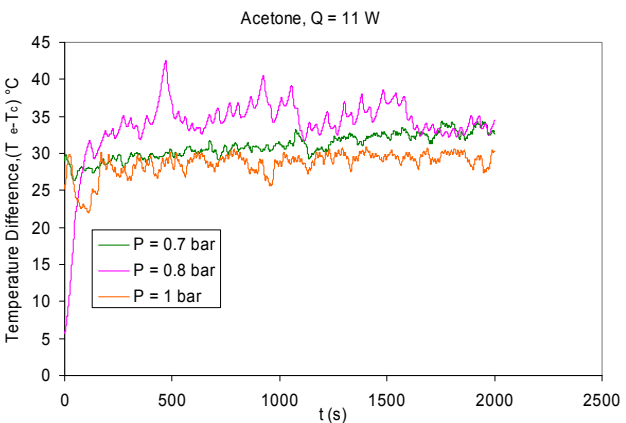

Fig. 6. Effect of evacuation on temperature difference for acetone at $\mathrm{Q}=11 \mathrm{~W}$

Figure 6 shows the variation of temperature difference between evaporator and condenser with time for different evacuation conditions for acetone at a heat input of $11 \mathrm{~W}$. From the figure it is clear that the temperature difference between the evaporator and condenser is slightly lower at atmospheric conditions compared to different evacuation levels. At atmospheric condition, the saturation temperature is higher 
compared to evacuated situation. Thus more liquid phase exists in the tube with a consequent increase in the heat transfer. Because of higher heat transfer from the wall to the fluid, the evaporator temperature reduces. Thus the temperature difference between evaporator and condenser reduces.

\subsection{Effect of Working Fluid on Temperature}

The variation of evaporator wall temperature with respect to time for different working fluids at an evacuation pressure of 0.7 bar and at a heat input of 12 $\mathrm{W}$ is shown in Fig. 7. From the figure it can be seen that the evaporator wall temperature is higher in case of ethanol and lower in the case of acetone due to higher saturation temperature for ethanol. It is also observed that the system takes more time to reach the steady state in case of ethanol compared to acetone. More fluctuations are observed in evaporator wall temperature of ethanol in view of its higher latent heat.

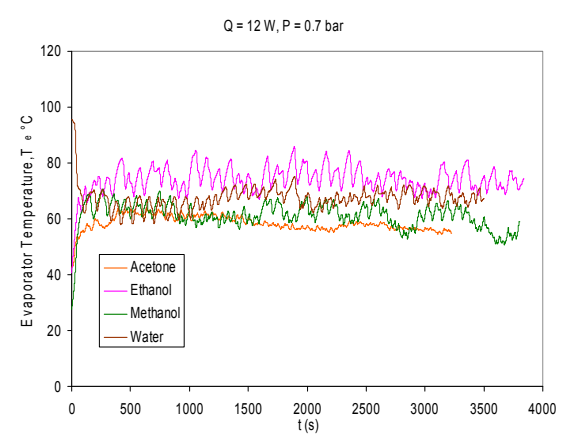

Fig. 7. Effect of working fluid on evaporator temperature at $\mathrm{Q}=12 \mathrm{~W}$ and $\mathrm{P}=0.7 \mathrm{bar}$

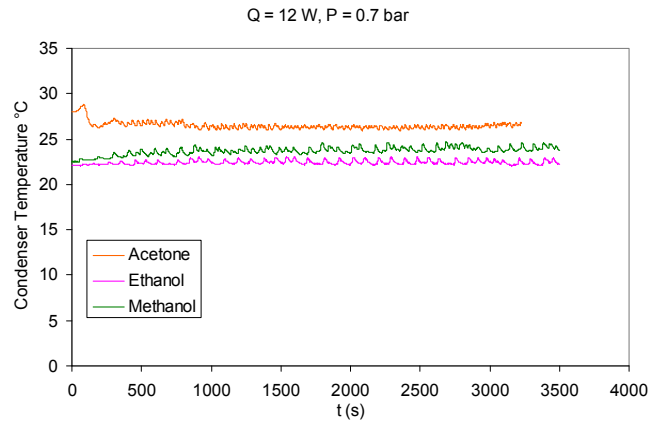

Fig. 8. Effect of working fluid on condenser temperature at $\mathrm{Q}=12 \mathrm{~W}$ and $\mathrm{P}=0.7$ bar

The variation of condenser wall temperature with time for different working fluids at an evacuation pressure of 0.7 bar and at a heat input of $12 \mathrm{~W}$ is reported in the Fig. 8. From Fig. 8, it is clear that the fluctuations in the condenser wall temperature are much lower compared to the wall temperature of the evaporator (Fig. 7). This is in view of single phase flow in the condenser and two phase flow in the evaporator. From the figure, it is also clear that the condenser wall temperature is lower for ethanol and higher for water and acetone. As there is an existence of less vapor while entering into the condenser in case of ethanol, only a small amount of heat will be released due to latent heat. Thus ethanol gets sub cooled to a greater extent. However, in case of acetone, the amount of vapor will be more when it enters the condenser and consequently the sub cooling effect will be much lower. This results in higher condenser wall temperature for acetone and lower condenser wall temperature for ethanol.

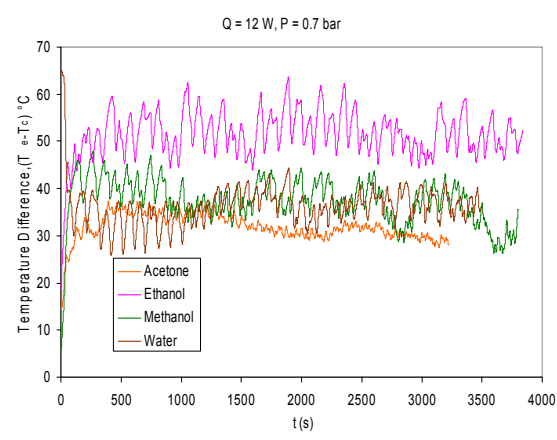

Fig. 9. Effect of working fluid on temperature difference at $\mathrm{Q}=12 \mathrm{~W}$ and $\mathrm{P}=0.7$ bar

Figure 9 shows the variation of temperature difference between evaporator and condenser with time for different working fluids at evacuation pressure of 0.7 bar and at a heat input of $12 \mathrm{~W}$. It is seen that the temperature difference between the evaporator and the condenser is less for acetone and more for ethanol. This is due to the fact that the saturation temperature of acetone is lower compared to ethanol. The fluctuations in temperature difference values are much lower for acetone compared to ethanol due to higher vapour contents in case of acetone. This shows that acetone can transfer heat with less temperature difference compared to ethanol. The temperature difference between evaporator and condenser for acetone is found to be around $34^{\circ} \mathrm{C}$ and for ethanol it is around $55^{\circ} \mathrm{C}$.

\subsection{Effect of Working Fluid on Thermal Resistance}

The Thermal Resistance of PHP is given by

$R=\frac{T_{e}-T_{c}}{Q}(\mathrm{~K} / \mathrm{W})$

Figure 10 shows the variation of thermal resistance with heat input for acetone under different evacuation conditions. From the figure it is clear that the thermal resistance decreases with increase in heat input at all evacuation conditions. The atmospheric conditions shows the lower values of thermal resistance compared to evacuation conditions. This shows that the heat transfer rate in PHP slightly reduces due to the formation of more vapor plugs with evacuation conditions.

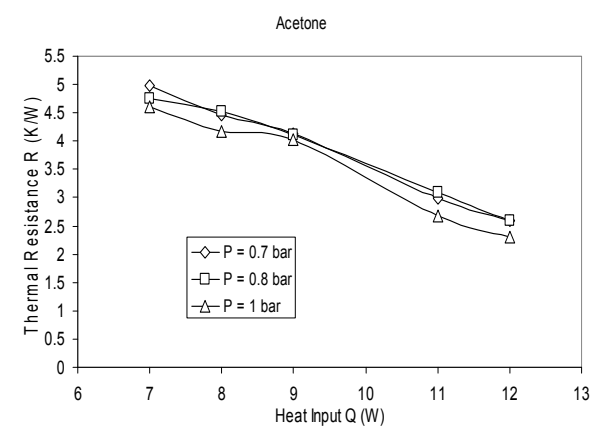

Fig. 10. Effect of vacuum and atmospheric pressure on thermal resistance for acetone 


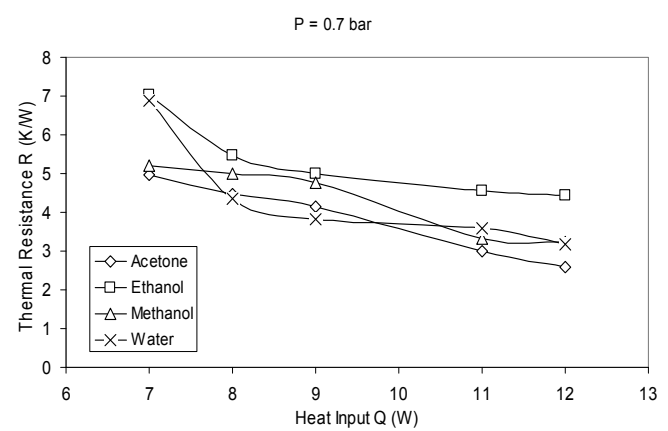

Fig. 11. Effect of working fluid on thermal resistance at $\mathrm{P}=0.7$ bar

Figure 11 shows the variation of thermal resistance with heat input for different working fluids at $\mathrm{P}=0.7$ bar. The figure shows that the thermal resistance decreases with increase in heat input in case of all the working fluids considered. Further, it is seen that acetone exhibits lower values of thermal resistance compared to other working fluids. This is due to lower value of temperature difference between evaporator and condenser in case of acetone. The lower values of thermal resistance of acetone indicate that acetone has better heat transport capability compared to other working fluids considered.

\subsection{Effect of Working Fluid on Heat Transfer Coefficient}

The heat transfer coefficient of a PHP is given by (Faghri 1995)

$$
h=\frac{Q}{A_{s}\left(T_{e}-T_{c}\right)}\left(\mathrm{W} / \mathrm{m}^{2}{ }^{0} \mathrm{C}\right)
$$

Figure 12 shows the variation of heat transfer coefficient with varying heat input for acetone for different evacuation pressures. From the figure, it is seen that the heat transfer coefficient increases with increase in heat input at all vacuum levels. Higher values of heat transfer co-efficient can be seen at atmospheric conditions indicating better heat transfer with less vapor plugs.

The variation of heat transfer coefficient with respect to heat input for different working fluids at an evacuation pressure of 0.7 bar is shown in Fig. 13. It is seen that the heat transfer coefficient increases with increase in heat input for all the working fluids considered. Acetone shows higher heat transfer coefficient values compared to other fluids considered. This is due to the lower values of temperature difference between evaporator and condenser for acetone.

\subsection{Power Spectral Density Analysis of PHP using FFT Technique}

The Power Spectral Density (PSD) analysis is usually made to extract the periodic features of a signal. If the power spectrum is continuous and asymptotic, the motion is considered as random. On the other hand, if the power spectrum has a sharp peak distribution at a dominant characteristic frequency, the motion is considered periodic (Xu and Zhang 2005). The PSD analysis is made through FFT and the higher power spectrum distribution corresponds to that there is a greater possibility at which the motion is in its corresponding frequency. Figure 14 shows the transient temperature distribution of PHP for ethanol at a heat input of $12 \mathrm{~W}$ for evaporator wall temperature $\mathrm{T}_{\mathrm{e}}$.

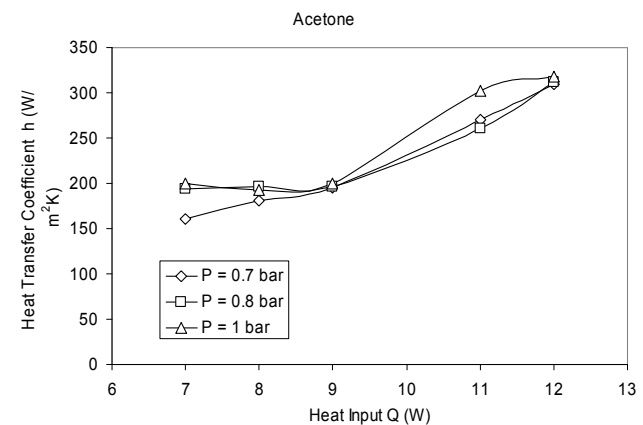

Fig. 12. Effect of vacuum and atmospheric pressure on heat transfer coefficient for acetone

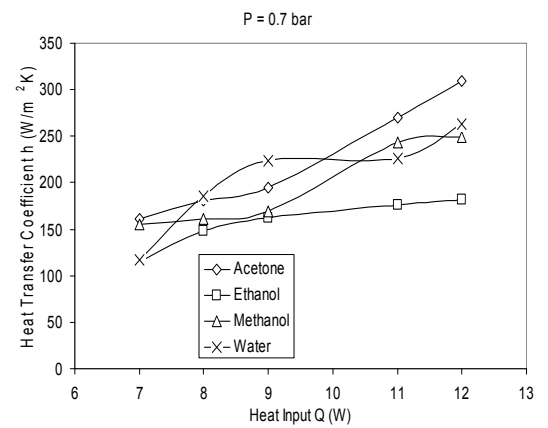

Fig. 13. Effect of working fluid on heat transfer coefficient at $\mathrm{P}=0.7 \mathrm{bar}$

The Power Spectrum Distribution (PSD) variation with frequency for the evaporator wall temperature of ethanol at $\mathrm{Q}=12 \mathrm{~W}$ is shown in Fig. 15. It is seen that such a power spectrum distribution has a frequency range between 0 to $0.03 \mathrm{~Hz}$. The dominant frequency of $0.0109 \mathrm{~Hz}$ is observed from Fig. 15 which corresponds to the dominant time period of $91.7 \mathrm{~s}$. It is to be noted that the dominant time period of $91.7 \mathrm{~s}$ from the PSD analysis is consistent with the average time period computed from the total time of 3840 s covered by 42 cycles as indicated in Fig. 14.

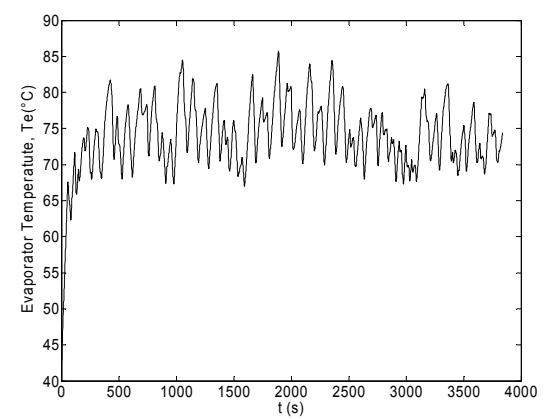

Fig. 14 .Transient evaporator temperature distribution for ethanol at $\mathrm{Q}=12 \mathrm{~W}$

The characteristic frequency corresponds to the characteristic time that a couple of adjacent vapour plug and liquid slug passing through a specific local wall surface. 


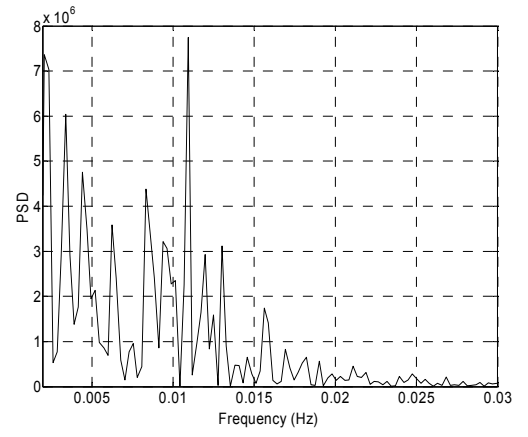

Fig. 15. PSD analysis of transient evaporator temperature of ethanol at $\mathrm{Q}=12 \mathrm{~W}$

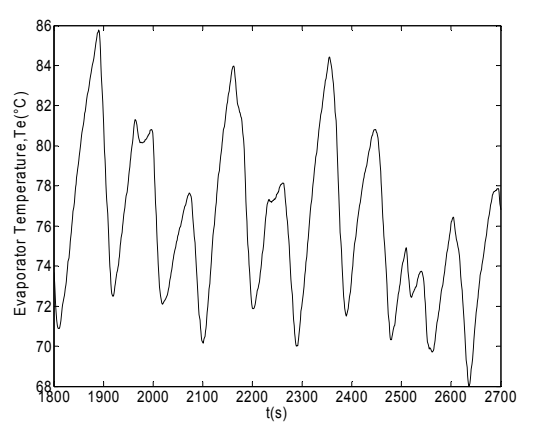

Fig. 16. Steady state evaporator temperature distribution for ethanol at $\mathrm{Q}=12 \mathrm{~W}$

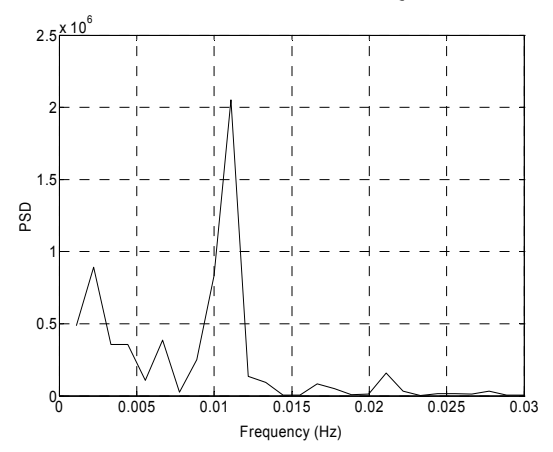

Fig. 17. PSD analysis of steady state evaporator temperature of ethanol at $\mathrm{Q}=12 \mathrm{~W}$

The lower frequency values indicate that the vapour plug and liquid slug distributed in the capillary tube of PHP are long at the heat input considered. The frequency distribution over a wider range signifies that the motion is random and the vapour plug and the liquid slug are randomly distributed in the capillary tube of $\mathrm{PHP}$ at the heat input considered (Xu and Zhang 2005).

Figure 16 shows the steady thermal oscillation of PHP for ethanol at a heat input of $12 \mathrm{~W}$ for evaporator temperature $T_{\mathrm{e}}$. These oscillations are considered in the time period range of $1800 \mathrm{~s}$ to $2700 \mathrm{~s}$. The PSD analysis is made for this steady thermal oscillations and the power spectrum distribution with respect to frequency for this steady temperature oscillations is shown in Fig. 17.

It is clear from Fig. 17 that the power spectrum distribution of steady thermal oscillation of PHP for ethanol at $\mathrm{Q}=12 \mathrm{~W}$ has a frequency range between 0 to
$0.03 \mathrm{~Hz}$. The dominant frequency of $0.0113 \mathrm{~Hz}$ is observed from Fig. 17 which corresponds to the dominant time period of $88.5 \mathrm{~s}$. It is to be noted that the dominant time period of $88.5 \mathrm{~s}$ from the PSD analysis is consistent with the average time period computed from the total time of $900 \mathrm{~s}$ covered by 10 cycles as indicated in Fig. 16. Lower PSD value is observed at steady thermal oscillation (Fig. 17) compared to transient temperature distribution (Fig. 15).

Figures 18, 20 and 22 show the steady state evaporator wall temperature distribution with time for methanol, water and acetone, respectively. Figures 19, 21 and 23 show the PSD analysis of these fluids. Table 1 gives the results of PSD analysis carried out at steady state for different fluids.

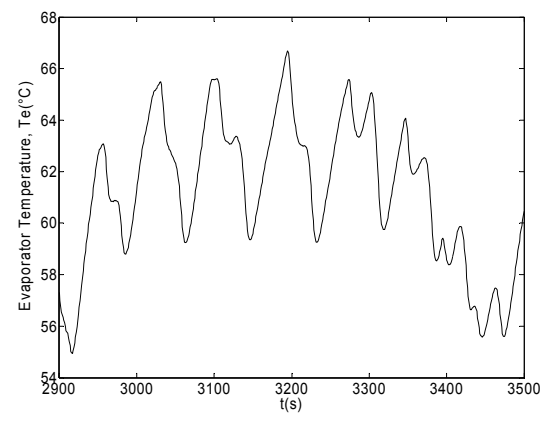

Fig. 18. Steady state evaporator temperature distribution for methanol at $\mathrm{Q}=12 \mathrm{~W}$

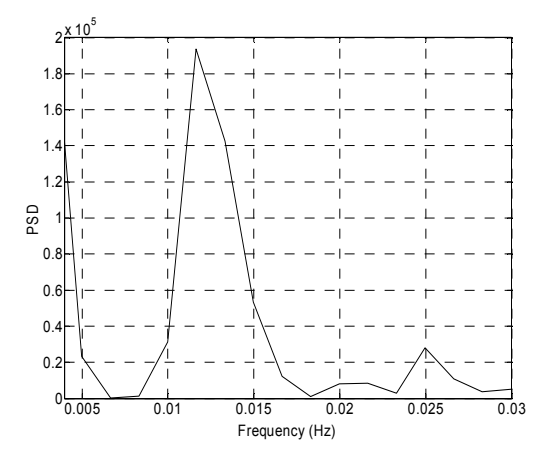

Fig. 19. PSD analysis of steady state evaporator temperature of methanol at $\mathrm{Q}=12 \mathrm{~W}$

\section{ConClusion}

The transient studies of PHP are presented exclusively in this work. The effects of heat input, thermal resistance and heat transfer coefficient on the performance of PHP are studied through experimentation. The Power Spectral Density analysis is carried out on the temperature fluctuations using FFT. The results of the present study are summarized as follows:

- The evaporator wall temperature variation is found to be periodic as ascertained from FFT analysis.

- The temperature difference between evaporator and condenser at steady state is found to be lower for acetone compared to water, ethanol and methanol. 


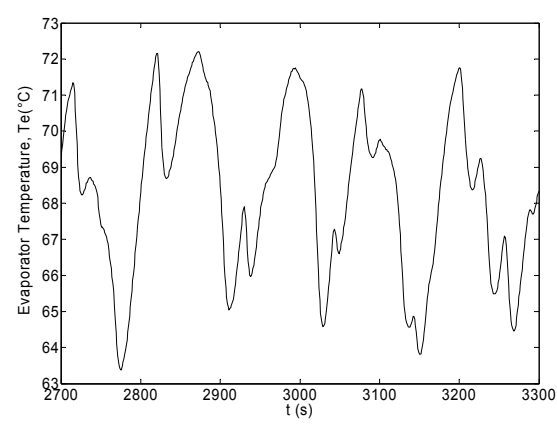

Fig. 20. Steady state evaporator temperature distribution for water at $\mathrm{Q}=12 \mathrm{~W}$

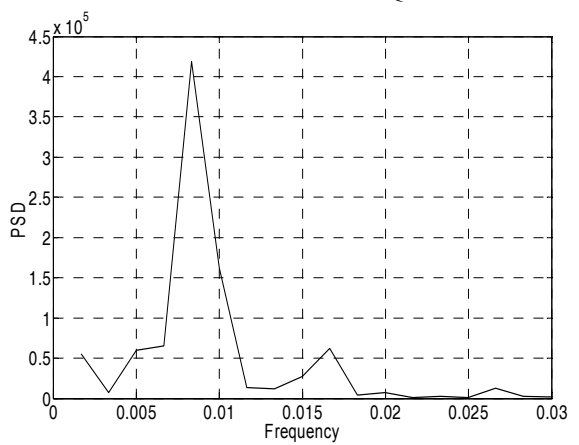

Fig. 21. PSD analysis of steady state evaporator temperature of water at $\mathrm{Q}=12 \mathrm{~W}$

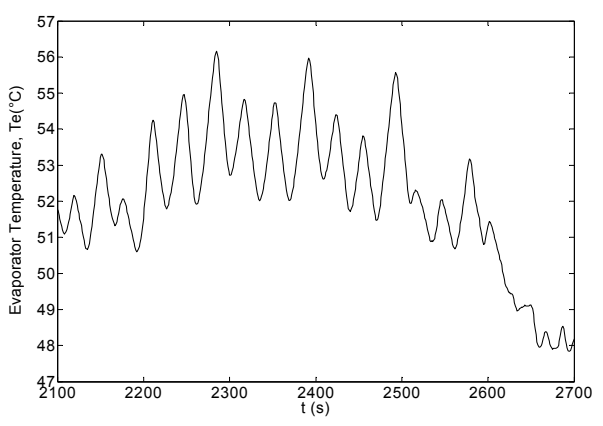

Fig. 22. Steady state evaporator temperature distribution for acetone at $\mathrm{Q}=11 \mathrm{~W}$

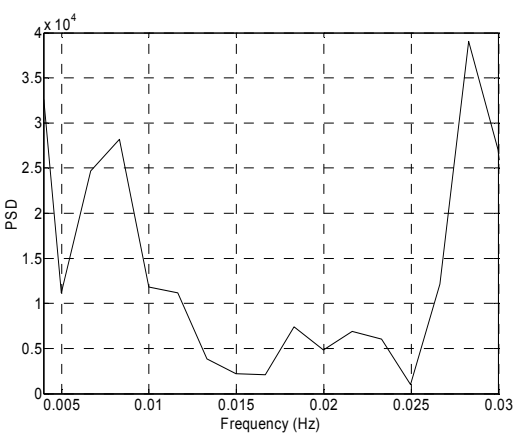

Fig. 23. PSD analysis of steady state evaporator temperature of acetone at $\mathrm{Q}=11 \mathrm{~W}$

Table 1 Results of PSD Analysis for different fluids at steady state

\begin{tabular}{|c|c|c|c|c|c|c|}
\hline Fluid & $\begin{array}{c}\text { Heat } \\
\text { Input } \\
\mathrm{Q}(\mathrm{W})\end{array}$ & $\begin{array}{c}\text { Time Period } \\
\text { Range (s) }\end{array}$ & $\begin{array}{c}\text { Frequency Range in } \\
\text { PSD Analysis (Hz) }\end{array}$ & $\begin{array}{c}\text { Dominant } \\
\text { Frequency (Hz) }\end{array}$ & $\begin{array}{c}\text { Dominant Time } \\
\text { Period (s) }\end{array}$ & $\begin{array}{c}\text { No. of } \\
\text { cycles }\end{array}$ \\
\hline Acetone & 11 & $2100-2700$ & $0-0.03$ & 0.0283 & 35.33 & 17 \\
\hline Methanol & 12 & $2900-3500$ & $0-0.03$ & 0.01165 & 84.84 & 7 \\
\hline Ethanol & 12 & $1800-2700$ & $0-0.03$ & 0.0113 & 88.5 & 10 \\
\hline Water & 12 & $2700-3300$ & $0-0.03$ & 0.00834 & 119.9 & 5 \\
\hline
\end{tabular}

- Large fluctuations are observed in wall temperature for ethanol compared to other fluids.

- Acetone is observed to be more suitable working fluid for PHP operation.

- The operation of a single loop PHP is found to be better at atmospheric conditions.

- The frequency of oscillations as determined from FFT analysis agrees well with that observed from flow visualization.

\section{ACKNOWLEDGEMENT}

The Authors thank Mr. Prashanth G.S., Mr. Pramod B.K., Mr. Nazeem, Mr. Harish K. of SBM Jain College of Engineering, Mr. Hemanth Kumar V. and Mr. Naveen T.N. of Centre for Emerging Technologies for their support during experimentation. The authors thank Mr. M.S. Ravi Kumar, Mr. R. Narasimha Rao, and Mr. R. Rama Krishna of $\mathrm{M} / \mathrm{s}$. Avasarala Automation,
Bangalore for their help in fabricating a sophisticated experimental setup and timely tips related to vacuum technology.

\section{REFERENCES}

Akachi, H. (1996). Structure of a Heat Pipe. US Patent, 5490558.

Akachi, H. (1993). Structure of a Heat Pipe. US Patent, 5219020.

Corey, A.W. (2006). Experimental Investigation of Nanofluid Oscillating Heat Pipes. M. Sc. Thesis, University of Missouri, Columbia.

Faghri, A. (1995). Heat Pipe Science and Technology. Taylor and Francis, Washington.

Khandekar, S. (2008, April). Multiple Quasi - Steady states in a closed loop Pulsating Heat Pipe. NTUSIITK 2nd Joint Workshop in Mechanical, 
K. Rama Narasimha et al. / JAFM, Vol. 5, No. 2, pp. 33-42, 2012.

Aerospace and Industrial Engineering, IIT, Kanpur, India.

Khandekar, S. (2004). Thermo Hydrodynamics of Pulsating Heat Pipes. Ph. D. Dissertation, University of Stuttgart, Germany.

Kline, S.J., K.N. and Mcclintock (1953). The descriptions of Uncertainties in single sample experiments. Mechanical Engineering 75.

Ma, H.B., B. Borgmeyer, P. Cheng, and Y. Zhang (2008). Heat Transport Capability in an oscillating Heat Pipe. ASME J. of Heat Transfer 130, 0815011 to $081501-7$.

Ma, H.B., M.A. Hanlon, C.L. Chen (2006). An Investigation of oscillating motions in a miniature pulsating heat pipe. Microfluidics and Nanofluidics 2, 171-179.

Piyanun Charoensawan, P., S. Khandekar, M. Groll, and P. Terdtoon (2003). Closed loop Pulsating Heat Pipes, Part - A: Parametric Experimental Investigations. Applied Thermal Engineering 23(16), $2009-2020$.

Rama Narasimha, K., S.N. Sridhara, M.S. Rajagopal, and K.N. Seetharamu (2010). Parametric Studies on Pulsating Heat Pipes. International Journal of Numerical Methods for Heat and Fluid Flow 20(4), 392 - 415.

Rama Narasimha, K., S.N. Sridhara, and M.S. Rajagopal (2008). Experimental Studies on Pulsating Heat Pipe. International Journal of Mechanical Engineering 1(1), 46 - 49.

Sakulchangsatjatai, P., T. Terdtoon, P. Wongratanaphisan, M. Kamonpet, and Murakami (2004). Operational modeling of closed end and closed loop oscillating heat pipes at normal operating condition. Applied Thermal Engineering $24,995-1008$.

Shafii, M.B., and A. Faghri (2002). Analysis of heat transfer in unlooped and looped pulsating heat pipes. International $J$. of Numerical Methods for Heat and Fluid Flow 12(5), 585 - 609.

Shafii, B.M., A. Faghri, and Y. Zhang (2001). Thermal modeling of unlooped pulsating heat pipes. ASME J. Heat Transfer 123(6), 1159-1172.

Xu, J.L., and X.M. Zhang (2005). Start-up and steady thermaloscillation of a Pulsating Heat Pipe. Heat and Mass Transfer 41, 685 - 694.

Zhang, X., M. Xu, and Z.Q. Zhou (2004). Experimental Study of a Pulsating Heat Pipe using FC - 72, Ethanol and Water as working fluids. Experimental heat Transfer 17, $47-67$.

Zhang, Y., and A. Faghri (2003). Oscillatory Flow in Pulsating Heat Pipes with Arbitrary number of turns. J. of Thermo Physics and Heat transfer 17(3), $340-347$.

Zhang, Y., and A. Faghri (2002). Heat Transfer in a pulsating heat pipe with open end. Int. J. Heat Mass Transfer 45(4), 755-764.

Zhang, Y., A. Faghri, and M.B. Shafii (2002). Analysis of liquid vapour pulsating flow in a U-shaped miniature tube. Int. J. Heat Mass Transfer45, 2501-2508. 